\title{
Stereotactic body radiotherapy for early-stage non-small cell lung cancer: clinical outcomes from a National Patient Registry
}

\author{
Joanne N. Davis • Clinton Medbery III • Sanjeev Sharma • David Perry • \\ John Pablo • David J. D'Ambrosio • Heidi McKellar • Frank C. Kimsey • \\ Paul N. Chomiak • Anand Mahadevan
}

Received: 16 October 2014 / Accepted: 18 December 2014 /Published online: 31 January 2015

(C) The Author(s) 2015. This article is published with open access at Springerlink.com

\begin{abstract}
Objectives Stereotactic body radiotherapy (SBRT) is a definitive local treatment option for patients with stage I non-small cell lung cancer (NSCLC) who are not surgical candidates and patients who refuse surgery. The purpose of this study was to assess the impact of SBRT on T1-T2 NSCLC from a national registry, reflecting practices and outcomes in a real-world setting.

Methods The RSSearch ${ }^{\circledR}$ Patient Registry was screened for T1-T2N0M0 NSCLC patients treated from May 2004 to May 2013 with SBRT. Descriptive analyses were used for patient, tumor, and treatment characteristics. Overall survival (OS) and local control (LC) were calculated using the KaplanMeier method.
\end{abstract}

\section{J. N. Davis}

The Radiosurgery Society, 1350 Dell, Suite 105, Campbell,

CA 95008, USA

e-mail: jdavis@therss.org

C. Medbery III

Department of Radiation Oncology, St. Anthony Hospital, Oklahoma

City, OK, USA

e-mail: buddy@swrads.org

\section{S. Sharma}

Department of Radiation Oncology, St. Mary's Medical Center,

Huntington, WV, USA

e-mail: sharmalahr@comcast.net

\section{Perry}

Department of Radiation Oncology, Medstar Franklin Square

Medical Center, Baltimore, MD, USA

e-mail: David.James.Perry@medstar.net

\section{J. Pablo}

Department of Radiation Oncology, St. Joseph/Candler Hospital,

Savannah, GA, USA

e-mail: drpablo@sjchs.org
Results In total, 723 patients with $517 \mathrm{~T} 1$ and $224 \mathrm{~T} 2$ lesions were treated with SBRT. Median follow-up was 12 months (1-87 months) with a median age of 76 years. Median SBRT dose was 54 Gy (range 10-80 Gy) delivered in a median of 3 fractions (range 1-5), and median biological equivalent dose $\left(\mathrm{BED}_{10}\right)$ was 151.2 Gy (range 20-240 Gy). Median OS was 30 and 26 months for T1 and T2 tumors, respectively ( $p=$ 0.019). $\mathrm{LC}$ was associated with higher $\mathrm{BED}_{10}$ for $\mathrm{T} 2$ tumors, but not in $\mathrm{T} 1$ tumors at a median follow-up of 17 months. Seventeen-month LC for T2 tumors treated with $\mathrm{BED}_{10}<$ $105 \mathrm{~Gy}, \mathrm{BED}_{10} 105-149$, and $\mathrm{BED}_{10} \geq 150$ Gy was 43,74 , and $95 \%$, respectively $(p=0.011)$. Local failure rates for $\mathrm{T} 2$ tumors treated with $\mathrm{BED}_{10}<105 \mathrm{~Gy}, 105-149 \mathrm{~Gy}$, and $\geq 150$ Gy were 32,21 , and $8 \%(p=0.029)$, respectively.

\section{J. D'Ambrosio}

Department of Radiation Oncology, New Jersey CyberKnife at

Community Medical Center, Toms River, NJ, USA

e-mail: DDAmbrosio@barnabashealth.org

\section{H. McKellar}

Department of Radiation Oncology, Eastern Texas Medical Center, Tyler, TX, USA

e-mail: heidilou65@yahoo.com

F. C. Kimsey

Department of Radiation Oncology, Erlanger Health System,

Chattanooga, TN, USA

e-mail: fckimsey@gmail.com

\section{P. N. Chomiak}

Thoracic Surgical Oncology, Sacred Heart Cancer Center, Pensacola, FL, USA

e-mail: paul.chomiak@shhpens.org

A. Mahadevan $(\varangle)$

Department of Radiation Oncology, Beth Israel Deaconess Medical

Center, Harvard Medical School, Boston, MA, USA

e-mail: amahadev@bidmc.harvard.edu 
Median OS for patients with $\mathrm{T} 2$ tumors treated with $\mathrm{BED}_{10}<$ 105 Gy was 17 vs. 32 months for T2 tumors treated with $\mathrm{BED}_{10} 105-149$ Gy $(p=0.062)$.

Conclusion SBRT for T1-T2 NSCLC is feasible and effective in the community setting. OS was greater for patients with $\mathrm{T} 1$ lesions compared to T2 lesions. An improvement in LC was observed in patients with $\mathrm{T} 2$ lesions treated with $\mathrm{BED}_{10}>$ 105 Gy.

Keywords Stereotactic body radiotherapy · Lung cancer . Non-small cell lung cancer $\cdot$ Registry $\cdot$ Radiosurgery

\section{Introduction}

The standard treatment for patients with stage I (IA and IB) non-small cell lung cancer (NSCLC) with no medical contraindication is surgery. Surgery results in a loco-regional control rate of $90 \%$ and a 5 -year overall survival rate of 50-70 \% for stage I NSCLC [1]. A significant number of early-stage lung cancer patients have co-morbidities which make them unsuitable for curative surgery. Radiation therapy is an alternative treatment for medically inoperable patients or patients who refuse surgery; however, conventional radiation therapy using 60 to 70 Gy results in relatively poor local control (30-70 \%) and survival $(15-30 \%)[2,3]$. Stereotactic body radiotherapy (SBRT) is a form of ablative radiation therapy which delivers high doses of radiation in fewer fractions compared to conventional radiation therapy. At the same time, SBRT allows to minimize the dose to surrounding the normal lung, often diseased in this population, making them poor candidates for surgery in the first place. Studies show that SBRT improves local control rates of early-stage NSCLC with a local control rate of $85-98 \%$ and 3-year overall survival rate of $48-65 \%$ [4-13]. SBRT has been shown to reduce local recurrence in borderline surgical candidates with early-stage I NSCLC compared to limited resection [14-16]. SBRT is now considered a standard treatment for inoperable stage I NSCLC and is being explored as a treatment option for medically operable patients [17]. However, the optimal treatment and schedule of SBRT for T1-T2N0M0 lung cancer are still being explored.

Based on available evidence, technical capability exists to perform SBRT in the community setting and is being routinely done. As the role for SBRT to treat NSCLC expands in controlled prospective clinical trials, it will be important to understand how SBRT is being implemented in the community setting and to investigate the clinical outcomes. Patient registries can be powerful tools to describe treatment management patterns, understand variations in treatment and outcomes, study generalizability of clinical trial results, and can complement data from randomized clinical trials. Another potential benefit of a registry is that data for patient demographics, treatment practices, and outcomes can be captured from a large number of patients rapidly. The RSSearch ${ }^{\circledR}$ Patient Registry was designed to standardize data collection for patients treated with SRS and SBRT and currently includes screening, treatment, and outcome data for over 14,000 patients treated with SRS/SBRT [18]. The purpose of this study was to examine disease presentation, treatment practices, and clinical outcomes of patients with T1-T2N0M0 NSCLC enrolled in RSSearch ${ }^{\circledR}$, thereby producing a real-world picture of disease, current treatment practices, and outcomes in radiation therapy using SBRT.

\section{Methods}

A retrospective analysis of patients with histologically proven T1-T2N0M0 NSCLC treated with SBRT and enrolled in the RSSearch ${ }^{\circledR}$ Patient Registry (Clinicaltrials.gov Identifier:NCT01885299) was performed. The RSSearch ${ }^{\circledR}$ Patient Registry is managed by the Radiosurgery Society, a non-profit professional medical society. A description of the methodology, database design, and initial patient and treatment characteristics of patients enrolled in RSSearch ${ }^{\circledR}$ has been previously reported [18]. The database is housed by an independent third party, Advertek ${ }^{\mathrm{SM}}$ (Louisville, KY), and meets all requirements to comply with the Health Insurance Portability and Accountability Act and Safe Harbor Policy to maintain system security, transmission of data, and patient confidentiality. All centers treating patients with SRS/SBRT clinically are offered and encouraged to participate in RSSearch ${ }^{\circledR}$. Participation is voluntary, and no compensation is provided either to patients or participating centers. Each principal investigator is provided a copy of the RSSearch ${ }^{\circledR}$ Registry protocol, case report forms, sample patient informed consent, and web-based training for data entry and database navigation. Institutional Review Board (IRB) approval is required at all participating centers. All procedures followed were in accordance with the ethical standards of the responsible committee on human experimentation (institutional and national) and with the Helsinki Declaration of 1975, as revised in 2008 (5). All patients who are screened for potential SRS/ SBRT treatment are eligible to be included in the RSSearch ${ }^{\circledR}$ Registry. Informed consent was obtained from all patients, as required by individual IRBs, prior to the patient's data entered into the RSSearch ${ }^{\circledR}$ Registry. Retrospective analysis of RSSearch $^{\circledR}$ is conducted from prospectively entered data. The selection of centers for this study included RSSearch ${ }^{\circledR}$ participating centers that treated NSCLC patients with SBRT between May 2004 and May 2013, with complete data entry fields for screening, treatment, and follow-up (minimum survival data) for their respective patients. For this analysis, 
NSCLC patients were treated at 14 institutions within the USA. Each center followed an independent Institutional Review Board (IRB)-approved protocol for RSSearch ${ }^{\circledR}$ participation.

Patients were treated with SBRT according to institutional guidelines. To compare the effects of various treatment protocols with different treatment fraction sizes and doses, the biological equivalent dose (BED) was calculated using the linear quadratic model, as $\mathrm{BED}=D \times(1+d / \alpha / \beta)$ where $D$ is the total dose, $d$ is the dose per fraction, and the $\alpha / \beta$ ratio for the tumor was $10 \mathrm{~Gy}$. Normal tissue dose restraints were reported by the treating institutions and captured in RSSearch ${ }^{\circledR}$ as the maximum point dose and interquartile range for each structure.

Patient follow-up was performed per institutional guidelines. All participating centers reported follow-up clinical and imaging data. Local control was evaluated independently for each lesion at the participating institution following a modified Response Evaluation and Criteria in Solid Tumors (RECIST) criteria. Lesion response was graded as either complete response (CR) defined as disappearance of all lesion/s treated, partial response (PR) defined as reduction in lesion size of lesions treated in by $30 \%$ or greater, and stable disease (SD) defined as neither sufficient shrinkage nor sufficient increase of size of lesions. Local progression was defined as at least a $20 \%$ increase in the size of lesions and/or appearance of one or more lesions in target treatment location and local control (LC) defined as disappearance of, decrease in, or no increase in size of the treated lesions. Analyses of LC, DC, and OS were calculated using the Kaplan-Meier method. LC was analyzed for each treated tumor whereas analysis of DC and OS was calculated for every patient. Specific cause of death was not reported for all patients in RSSearch ${ }^{\circledR}$ and therefore not evaluated in this study. Subgroups were compared using $X^{2}$ and log-rank statistics. Values of $p<0.05$ were considered statistically significant. Statistical calculations were conducted using Instat and GraphPad Prism (La Jolla, CA).

\section{Results}

Demographics and lesion characteristics

In total, 723 patients with 741 lesions diagnosed with T1-T2 primary NSCLC lung cancer between May 2004 and May 2013 were included in this study. The median age was 76 years (range $41-95$ years), $52 \%$ were female and $48 \%$ were male (Table 1); $88 \%$ were Caucasian, $6 \%$ African-American, and $0.7 \%$ Hispanic. The median Karnofsky Performance Score was 80 (range 40-100). Three hundred seventy-four patients (52\%) were considered medically inoperable, 111 patients
Table 1 Patient characteristics and demographics

\begin{tabular}{lc}
\hline Variable & Number \\
\hline Gender: $n=723$ patients & \\
Male & $349(48 \%)$ \\
Female & $374(52 \%)$ \\
Median age in years (range) & $76(41-95)$ \\
Median weight in lbs (range) & $160(60-330)$ \\
Median Karnofsky performance score (range) & $80(40-100)$ \\
Median VAS Pain Score (range) & $0(0-9)$ \\
Current or previous smoker & $630(87 \%)$ \\
Median smoker pack/years (range) & $50(1-545)$ \\
Race/ethnicity & \\
Caucasian & $634(88 \%)$ \\
Black/African American & $42(6 \%)$ \\
Hispanic & $5(0.7 \%)$ \\
Other & $2(0.3 \%)$ \\
Unknown & $39(5 \%)$ \\
Medically inoperable & $374(52 \%)$ \\
Surgically inoperable & $111(15 \%)$ \\
Prior Treatment(s): $n=741$ lesions & \\
None & $622(84 \%)$ \\
Chemotherapy & $69(9 \%)$ \\
Surgery & $17(2 \%)$ \\
External beam radiation & $9(1 \%)$ \\
Radiosurgery & $3(0.4 \%)$ \\
Radiofrequency ablation & $3(0.4 \%)$ \\
\hline
\end{tabular}

(15\%) were surgically inoperable, and the rest refused surgery. The primary co-morbidities for medically inoperable patients included pulmonary $(n=258)$, cardiac $(n=66)$, vascu$\operatorname{lar}(n=9)$, and advanced age with poor performance status $(n=$ 6). Eighty-four percent of patients had no prior treatment, $9 \%$ had received chemotherapy, $2 \%$ had undergone surgery, and $1 \%$ had received external beam radiation therapy. Patients were most commonly referred to the radiation oncology department for SBRT evaluation by medical oncology (37\%), followed by pulmonology (21\%), cardio-thoracic surgery (17\%), other radiation oncology (10\%) departments, and self-referral (3\%). Medicare was listed as the primary payer for $72 \%$ of patients, private insurance for $17 \%$, Medicaid for $2 \%$, Veterans Administration for $2 \%$, and uninsured/self-pay for 1 patient.

The lesion characteristics are shown in Table 2. Seventy percent of lesions were T1 $(n=517)$ and $30 \%$ were T2 $(n=$ 224). The median lesion volume was $14.9 \mathrm{cc}$, and the median maximal tumor diameter was $2.4 \mathrm{~cm}$ (range $0.2-6.5 \mathrm{~cm}$ ). Twenty-four patients had more than one lung tumor treated with SBRT (range 1-4 lesions). Pathological diagnosis was completed for all patients, and the histological subtypes were reported as adenocarcinoma $(n=248)$, NSCLC $(n=238)$, 
Table 2 Lesion and SBRT treatment characteristics

\begin{tabular}{|c|c|}
\hline Variable & Number \\
\hline T1N0M0 & $517(70 \%)$ \\
\hline T2N0M0 & $224(30 \%)$ \\
\hline \multicolumn{2}{|l|}{ Histology: } \\
\hline Adenocarcinoma & $248(33 \%)$ \\
\hline Non-small cell carcinoma & $238(32 \%)$ \\
\hline Squamous cell carcinoma & $224(30 \%)$ \\
\hline Large cell carcinoma & $16(2 \%)$ \\
\hline Bronchiolo-alveolar carcinoma & $15(2 \%)$ \\
\hline Median lesion volume, cc (range) & $14.9(0.5-334)$ \\
\hline Median lesion size, long axis, cm (range) & $2.4(0.2-6.5)$ \\
\hline \multicolumn{2}{|l|}{ Lesion location } \\
\hline Right upper lobe & $197(27 \%)$ \\
\hline Right middle lobe & $38(5 \%)$ \\
\hline Right lower lobe & $116(16 \%)$ \\
\hline Right lobe, NOS & $5(2 \%)$ \\
\hline Left upper lobe & $185(25 \%)$ \\
\hline Left middle lobe & $13(2 \%)$ \\
\hline Left lower lobe & $94(13 \%)$ \\
\hline Left lobe, NOS & $9(1 \%)$ \\
\hline Bronchus & $3(0.4 \%)$ \\
\hline Not indicated & $81(11 \%)$ \\
\hline Median SBRT dose (range), Gy & $54(10-80)$ \\
\hline Median number of fractions & $3(1-5)$ \\
\hline Median $\mathrm{BED}_{10}$ dose, Gy & $151.2(2-240)$ \\
\hline \multicolumn{2}{|l|}{ Most common dose/fraction schemes: } \\
\hline $20 \mathrm{~Gy} \times 3=60 \mathrm{~Gy}$ & $219(30 \%)$ \\
\hline $18 \mathrm{~Gy} \times 3=54 \mathrm{~Gy}$ & $162(22 \%)$ \\
\hline $10 \mathrm{~Gy} \times 5=50 \mathrm{~Gy}$ & $79(11 \%)$ \\
\hline $12.5 \mathrm{~Gy} \times 4=50 \mathrm{~Gy}$ & $78(11 \%)$ \\
\hline $12 \mathrm{~Gy} \times 4=48 \mathrm{~Gy}$ & $45(6 \%)$ \\
\hline $12 \mathrm{~Gy} \times 5=60 \mathrm{~Gy}$ & $25(3 \%)$ \\
\hline Median Dmax (range), Gy & $72.7(10-113)$ \\
\hline Median monitor units & $39,373(5614-102,565)$ \\
\hline
\end{tabular}

squamous cell carcinoma $(n=224)$, bronchiolo-alveolar carcinoma $(n=15)$, and large cell carcinoma $(n=16)$.

\section{SBRT treatment}

SBRT was indicated as the primary treatment for $91 \%(n=$ $675)$ of lesions and adjuvant treatment for $8 \%(n=61)$ lesions. Treatment indication was not reported for five patients. The most common SBRT dose-fractionation schedules are shown in Table 2 and include 60 Gy in 3 fractions $(n=219), 54$ Gy in 3 fractions $(n=162), 50$ Gy in 5 fractions $(n=79), 50$ Gy in 4 fractions $(n=78)$, and 48 Gy in 4 fractions $(n=45)$. The median dose was 54 Gy delivered in 3 fractions, and the median $\mathrm{BED}_{10}$ was 151.2 Gy (range, 20-240 Gy). The median maximum point dose (Dmax) to the target was 72.7 Gy (range 10-113 Gy).

Doses to organs at risk (OAR) were reported in $\mathrm{RSSearch}^{\circledR}$ as the Dmax for each individual OAR. Table 3 shows the median Dmax (range, 25th percentile and 75th percentile) for the esophagus, brachial plexus, trachea, main bronchus, heart, major vessels, and spinal cord. The median Dmax for esophagus, brachial plexus, trachea, main bronchus, heart, major vessels, and spinal cord were 9.9, 18.6, 13.5, 14.5, $12.5,18.3$, and $7.2 \mathrm{~Gy}$, respectively. For comparison, the dose tolerance limits are also shown for Radiation Therapy Oncology Group (RTOG) 0236 protocol for medically inoperable patients treated with 54 Gy delivered in 3 fractions [7]. For all OARs, the dose reported at the 75th percentile was below the maximum dose limits specified in RTOG 0236.

Overall survival (OS), local control (LC), and distant disease control (DC)

The median follow-up was 12 months (range 1-87 months). Kaplan-Meier curves for survival are shown in Fig. 1. The median OS for the entire group was 29 months $(95 \% \mathrm{CI}$, 23-34 months). The median OS of patients with T1 and T2 tumors was 30 and 26 months, respectively $(p=0.019$; Fig. 1a). One-year OS was $85 \%$ (95\% CI, 81-88\%) for T1 and $76 \%$ (95\% CI, 68-81\%) for T2 tumors. The 2-year OS rate was $63 \%(95 \% \mathrm{CI}, 56-69 \%)$ for T1 and $52 \%(95 \% \mathrm{CI}$, 42-60\%) for T2 tumors.

Four hundred and thirty-four lesions from 429 patients were evaluated for tumor response. A reduction in tumor size

Table 3 Doses to normal adjacent structures

\begin{tabular}{lllll}
\hline Organ & Dmax, 25th Percentile (Gy) & Median Dmax (range) & Dmax, 75th Percentile (Gy) & Max dose constraints, RTOG 0236 [7] \\
\hline Esophagus & 6 & 9.9 Gy $(0-51.1)$ & 16 & 27 Gy max \\
Brachial plexus & 4 & 18.6 Gy $(0.02-43.5)$ & 23.5 & 24 Gy max \\
Trachea & 7 & 13.5 Gy $(0-64.9)$ & 26 & 30 Gy max \\
Main bronchus & 8 & 14.5 Gy $(0-63.0)$ & 28 & 30 Gy max \\
Heart & 7 & 12.5 Gy $(0-96)$ & 20 & 30 Gy max \\
Major vessels & 10 & $18.3(0.1-64)$ & 34 & 39 Gy \\
Spinal cord & 4.5 & $7.2(0-75)$ & 11.8 & 18 Gy \\
\hline
\end{tabular}


A

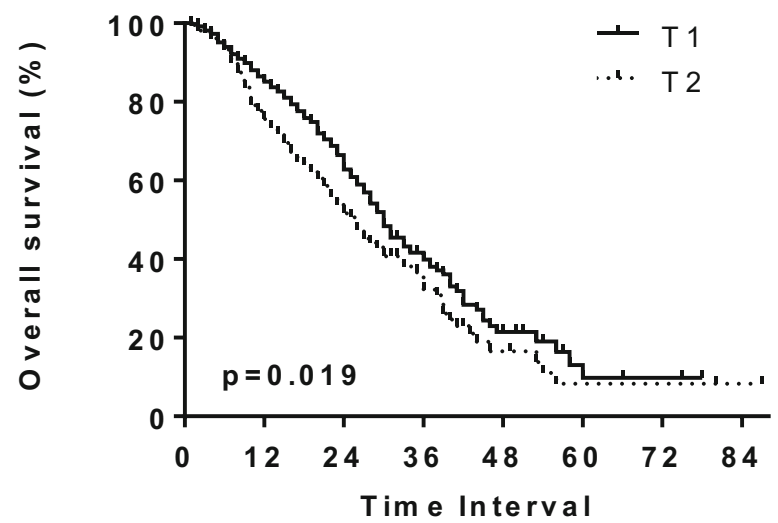

B

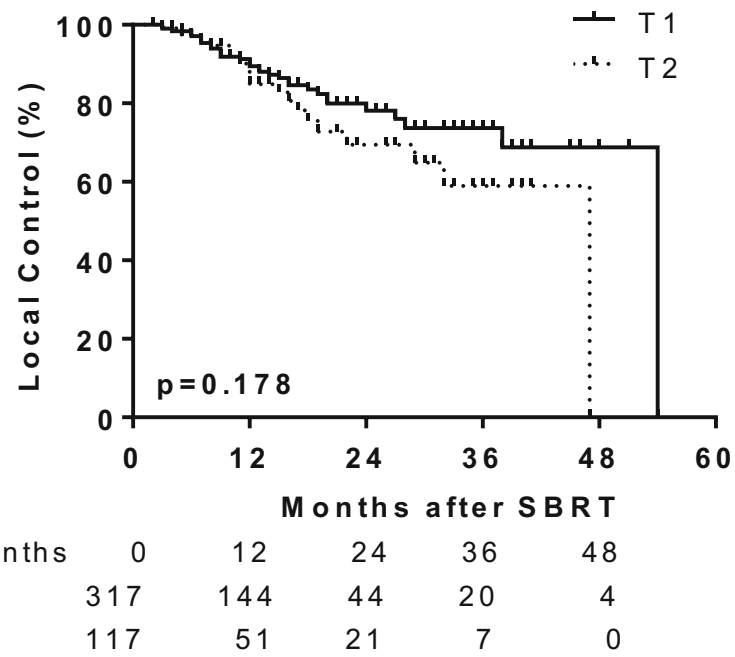

C

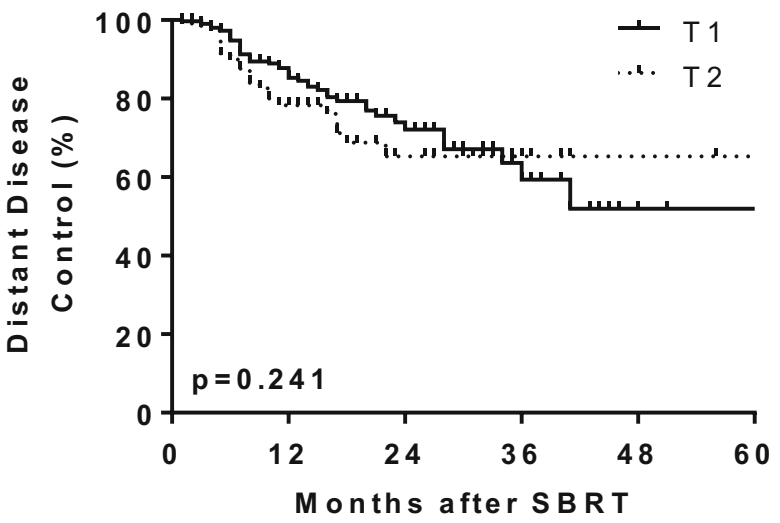

$\begin{array}{lrrrcccrr}\text { Months } & 0 & 12 & 24 & 36 & 48 & 60 & 72 & 84 \\ \text { N, T1 } & 509 & 257 & 107 & 48 & 13 & 4 & 2 & 0 \\ \text { N, T2 } & 214 & 109 & 51 & 25 & 8 & 4 & 4 & 2\end{array}$

Fig. 1 Survival curves for T1 and T2 lesions treated with SBRT. KaplanMeier analysis of overall survival (a), local control (b), and distant disease control (c) for patients with T1 (solid lines) and T2 (dotted lines) NSCLC treated with SBRT. Ticked marks indicate censored patients. Patients with T1 lesions had greater overall survival compared to T2 lesions ( $p=0.019$ by log-rank test)

was reported in 254 lesions ( $59 \%$ ) with a complete response reported in 131 lesions and partial response reported in 123 lesions. Stable disease was reported in $62(14 \%)$ lesions. Local failure was reported in 57 lesions (13\%). One-year LC was $88 \%(95 \%$ CI, 84-92\%) and 2-year LC was $76 \%$ (95\% CI, 68-82\%). When stratified by T-classification, 1year LC was $89 \%(95 \% \mathrm{CI}, 84-93 \%)$ for T1 and $85 \%(95 \%$ CI, 74-91\%) for T2 tumors (Fig. 1b). The median time to local failure was 54 and 47 months for T1 and T2 tumors, respectively $(p=0.178)$. Seventy-six patients were reported to have distant disease progression. One-year DC was $85 \%$ (95\% CI, 80-89\%) and $78 \%$ (95\% CI, 68-86\%) for T1 and T2 tumors, respectively (Fig. 1c).

$\mathrm{BED}_{10}$ was calculated for each dose/fractionation regimen, and $\mathrm{LC}$ and OS were assessed for patients who received BED $_{10}<105$ Gy vs. BED $10105-149$ Gy vs. BED $_{10} \geq$ $150 \mathrm{~Gy}$. Local failure was associated with lower $\mathrm{BED}_{10}$ for T2 lesions. Local failure occurred in $32 \%$ of patients treated with $\mathrm{BED}_{10}<105$ Gy vs. $21 \%$ for $\mathrm{BED}_{10} 105-149 \mathrm{~Gy}$ vs. $8 \%$ for $\mathrm{BED}_{10} \geq 150$ Gy $\left(p=0.029\right.$ by $X^{2}$ test; Table 4$)$. Median time to local failure was 17 months for T2 tumors treated with $\mathrm{BED}_{10}<105 \mathrm{~Gy}$ and not reached for $\mathrm{BED}_{10} \geq 105$. The 17month LC rate was $43 \%(95 \% \mathrm{CI}, 15-71 \%)$ for $\mathrm{BED}_{10}<$ $105 \mathrm{~Gy}, 74 \%$ (95 \% CI, 50-88 \%) for BED 10 105-149 Gy, and $95 \%(95 \% \mathrm{CI}, 81-99 \%)$ for $\mathrm{BED}_{10} \geq 150 \mathrm{~Gy}(p=0.011$; Fig. 2a). There was no difference in local failure rates for $\mathrm{T} 1$ tumors treated with the different $\mathrm{BED}_{10}$ doses. Local failure was reported in $15 \%$ of $\mathrm{T} 1$ lesions treated with BED10< $105 \mathrm{~Gy}, 11 \%$ for $\mathrm{BED}_{10} 105-149 \mathrm{~Gy}$, and $11 \%$ for $\mathrm{BED}_{10} \geq 150$ Gy ( $p=0.713$ by $X^{2}$; Table 4$)$. The 1 -year LC rate for $\mathrm{T} 1$ lesions was $84 \%$ (95\% CI, 69-92\%) for $\mathrm{BED}_{10}<105 \mathrm{~Gy}, 85 \%$ (95\% CI, 71-93\%) for $\mathrm{BED}_{10} 105$ $149 \mathrm{~Gy}$, and $93 \%$ (95\% CI, 87-97\%) for $\mathrm{BED}_{10} \geq 150 \mathrm{~Gy}$ (Fig. 2c).

For patients with $\mathrm{T} 2$ lesions treated with $\mathrm{BED}_{10}>105 \mathrm{~Gy}$, there was a trend for improved OS, although it did not reach statistical significance. The 1-year OS rate for T2 lesions treated with $\mathrm{BED}_{10}<105 \mathrm{~Gy}, \mathrm{BED}_{10} 105-149 \mathrm{~Gy}$, and $\mathrm{BED}_{10} \geq$

Table 4 Local failures for $\mathrm{T} 1$ and $\mathrm{T} 2$ tumors stratified by $\mathrm{BED}_{10}$

T stage $\quad \mathrm{BED}<105$ Gy $\quad \mathrm{BED} 105-149$ Gy $\quad \mathrm{BED} \geq 150$ Gy $\quad p$ value $\left(X^{2}\right.$ test $)$

$\begin{array}{lrrrrrr}\text { Months } & 0 & 12 & 24 & 36 & 48 & 60 \\ \text { N, T1 } & 314 & 139 & 40 & 15 & 3 & 2 \\ \text { N, T2 } & 114 & 47 & 18 & 6 & 3 & 2\end{array}$

\begin{tabular}{llrcl}
\hline T1 & $8 / 55(15 \%)$ & $10 / 92(11 \%)$ & $18 / 170(11 \%)$ & 0.713 \\
T2 & $8 / 25(32 \%)$ & $9 / 42(21 \%)$ & $4 / 50(8 \%)$ & $0.029^{\mathrm{a}}$ \\
\hline
\end{tabular}

${ }^{\mathrm{a}}$ Indicates statistically significant value 
A

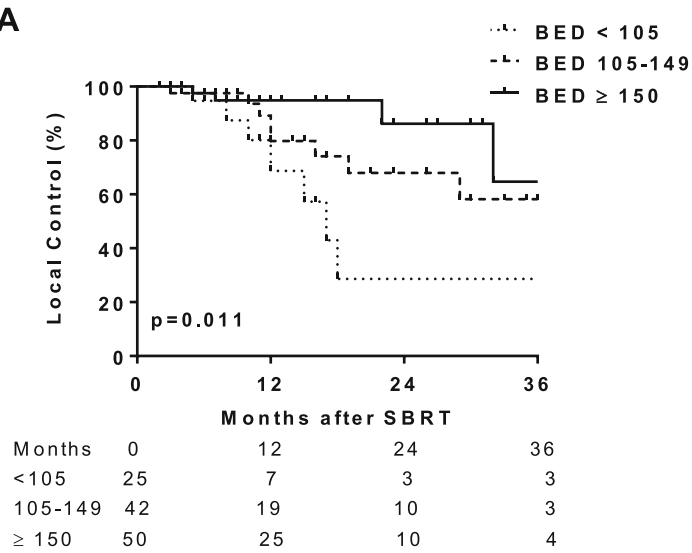

B

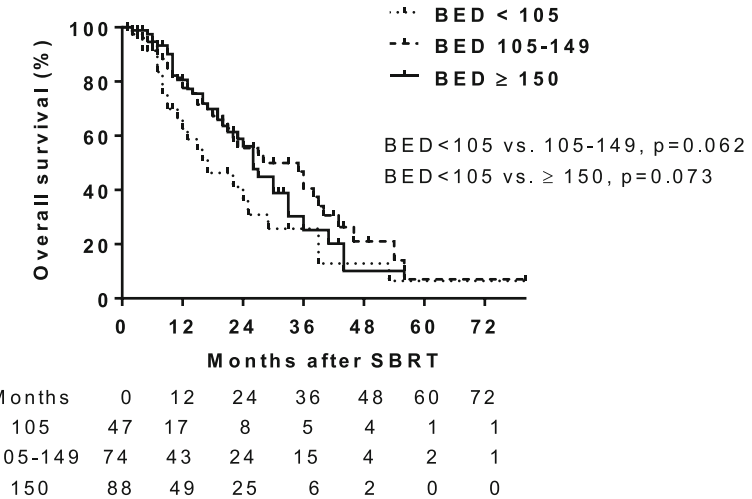

C

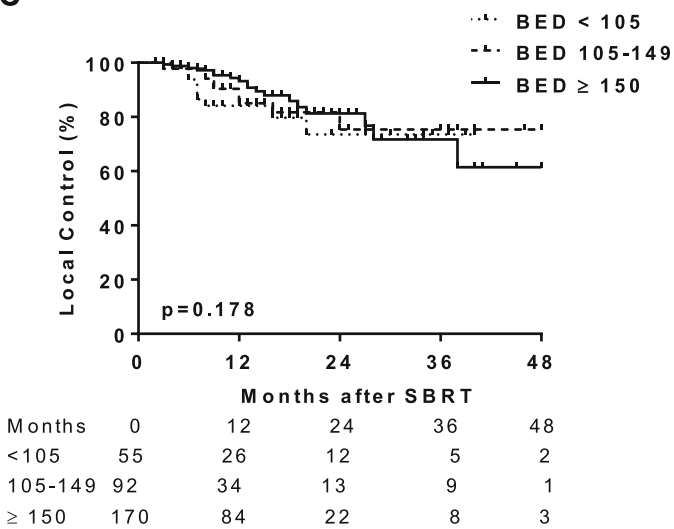

D

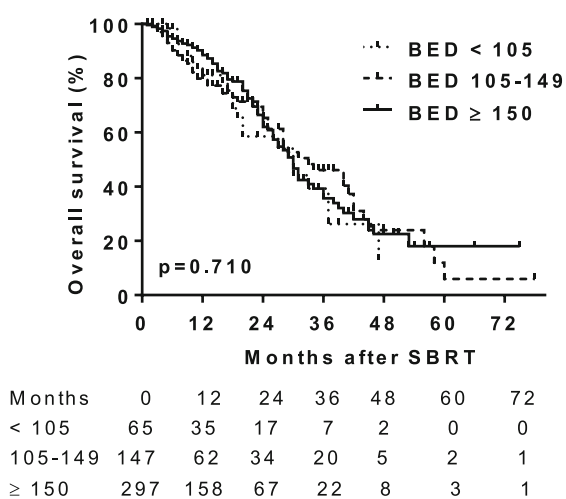

marks indicate censored patients. LC improved for T2 lesions treated with $\operatorname{BED} 10$ ( $p=0.011$ by log-rank test), but not T1 lesions. There was a trend for improved OS for T2 lesions treated with BED10105-149 compared to BED $10<105$ although it did not reach statistical significance $(p=0.062$ by log-rank test)

of the current analysis was to evaluate the current management practices and outcomes of SBRT for early-stage lung cancer in a real-world setting. Our results demonstrate that participating centers are adhering to recommended treatment guidelines and published reports for SBRT treatment of T1T2 lung cancer. The LC and OS rates reported in this study are in line with previous published reports of single institution, retrospective, and prospective studies $[4,5,7-10,12,13$, 19-21].

We acknowledge that this study is an observational study and that only randomized controlled clinical trials can conclusively determine survival benefits and differences in outcomes from treatment parameters; however, no such comparative efficacy or dose-escalation studies or data currently exist for SBRT for early-stage lung cancer. In the absence of this data, patient registries can provide important information to identify new treatment regimens, identify patients that may be most beneficial to treatments, generate new hypotheses on doseresponse and response assessment, and thereby complement 
randomized clinical trials. In this study, we identified improved LC and improved OS in patients with $\mathrm{T} 2$ lesions treated with SBRT doses of $\mathrm{BED}_{10}>105 \mathrm{~Gy}$. Evidence exists for a dose-response relationship with standard fractionated radiotherapy and stage I NSCLC $[22,23]$. Published results on dose-response relationships with SBRT and stages I-II NSCLC have been limited and controversial. Onishi et al. reported improved LC and OS in 257 patients with $\mathrm{BED} \geq$ 100 Gy compared to BED $<100$ Gy [6]. Grills et al. reported that $\mathrm{BED}_{10}$ predicted local relapse and distant metastasis in patients with T1-T3 N0M0 NSCLC with a 2-year local relapse of $15 \%$ for $\mathrm{BED}_{10}<105$ Gy vs. $4 \%$ for BED $10 \geq 105$ [5]; however, $\mathrm{BED}_{10}$ dose relationships to local relapse were not stratified by T-classification in this study. In contrast, Stephans et al. did not find improvement for OS, LC, nodal failure, or distant metastasis in patients who received $60 \mathrm{~Gy}$ in 3 fractions $\left(\mathrm{BED}_{10}=180 \mathrm{~Gy}\right)$ compared to patients who received 50 Gy in 5 fractions $\left(\mathrm{BED}_{10}=100 \mathrm{~Gy}\right)$; however, the follow-up was limited with a median of 9.5 months (range 2.1-19.5 months) for patients $(n=38)$ that received $60 \mathrm{~Gy}$ in 3 fractions [24]. In our current study, the median time to local failure for $\mathrm{T} 2$ lesions with $\mathrm{BED}_{10}<105$ Gy was 17 months and not met for $\mathrm{BED}_{10}>105 \mathrm{~Gy}$, suggesting that follow-up longer than 17 months is needed to detect differences between BED $<$ 105 vs. $>105$ Gy. Several studies using CyberKnife Robotic Radiosurgery System have reported a dose response for LC of early-stage lung cancer $[21,25,26]$. Le et al. reported 1-year LC rate of $91 \%$ for patients treated with a single fraction of greater than 20 Gy vs. $54 \%$ for patients who received a single fraction of less than $20 \mathrm{~Gy}$ [25]. Nuyttens et al. reported 2-year LC rate of $85 \%$ for patients with centrally located tumors who received $\mathrm{BED}>100$ Gy (60 Gy delivered in 5 fractions) vs. $60 \%$ for patients who received BED $\leq 100$ Gy (45-50 Gy delivered in 5 fractions) [26]. van der Voort van Zyp et al. reported a $95 \%$ LC for stage I patients who received 60 Gy delivered in 3 fractions vs. $78 \%$ for patients who received 45 Gy delivered in 3 fractions [21]. In these studies, the effect of dose on T1 vs. T2 tumors was not studied. Onimaru et al. reported improved LC and $\mathrm{OS}$ in IB tumors treated to 48 Gy compared to 40 Gy delivered in four fractions, but did not find a response in IA lesions and suggested dose-response relationships may be related to tumor size [27].

There are several limitations of this study. First, as is common to registries, the patient inclusion criteria are not exclusively defined and the patient cohort represents a heterogeneous population. Our cohort included tumor sizes up to $6.5 \mathrm{~cm}$, including an assortment of peripheral and centrally located tumors. Patients were also treated with a wide range of dose/fractionation schemes. Despite these variations, the LC rate in our study was $90 \%$ and higher for T1 and T2 lesions treated with BED $>150$ Gy and in line with previously published reports [5, 21, 25, 26, 28].
Another limitation of multi-institutional registries is obtaining complete follow-up information. While the majority of follow-up information was available, not all patients' tumor response assessment was reported. Also, evaluation of recurrence did not require histological confirmation and relied on non-invasive tests including CT and PET. This is not uncommon in routine clinical practice. More importantly, this study did not report on toxicities consistently at this time and the causes of death are not always recorded. As this and other registries continue to mature, these aspects will be addressed and future studies on acute and late toxicities will be reported. Further long-term follow-up is warranted to determine whether the outcomes observed in this initial report will persist at 5 years and beyond.

Although SBRT for stage I lung cancer has been available for several years, there are continuous improvements in technology and expansion of indications for SBRT lung treatments. The RSSearch ${ }^{\circledR}$ Patient Registry continues to capture patient data, reflecting the treatment patterns and clinical outcomes from the real world. An advantage of patient registries is the ability to capture data on a large number of patients in a short time and report on outcomes rapidly. When information capture, including patient and treatment characteristics and follow-up data including response assessment and toxicity is done more rigorously, such studies could complement and validate results from randomized studies. Moreover, this may be a robust avenue to study applicability and generalizability of randomized clinical trials in the real-world community setting.

\section{Conclusions}

We report on one of the largest multi-center datasets of earlystage NSCLC patients treated with SBRT and report on the current treatment management practices and outcomes in the community. Registries are useful tools to assess management practices and outcomes in the real world. Local control and survival outcomes for stage I NSCLC are not dissimilar to single institutional and prospective studies. Additionally, an improvement in LC was observed in patients with $\mathrm{T} 2$ lesions treated with $\mathrm{BED}_{10}>105 \mathrm{~Gy}$, supporting a dose response, which was not seen in patients with $\mathrm{T} 1$ lesions.

Acknowledgments We would like to thank the numerous institutions, physicians, and health care personnel who enrolled patients in this registry, as well as the patients who agreed to participate in the RSSearch ${ }^{\circledR}$ Registry. We would like to acknowledge the following centers who contributed patient data to this study: CyberKnife Center of St. Francis Hospital, Memphis, TN, Mercy Hospital, Springfield, MO, Waukesha Memorial Hospital, Waukesha, WI, St. Joseph's Hospital, St. Paul, MN, Memorial Hospital West, Hollywood, FL, and Multicare Regional Cancer Center, Tacoma, WA. We would also like to thank Nalani Brown of the Radiosurgery Society for her administrative oversight of the RSSearch ${ }^{\circledR}$ Patient Registry. 
Conflict of interest Frank Kimsey has stock ownership in CyberKnife of Chattanooga, LLC. Joanne Davis has stock in Accuray Inc. Clinton Medbery III, Sanjeev Sharma, David Perry, John Pablo, David D'Ambrosio, Heidi McKellar, Paul Chomiak, and Anand Mahadevan declare that they have no conflict of interest.

Author's contributions CM, SS, DP, JP, DD, HK, FK, and PC contributed to patient treatment and care and data collection. JD and AM conducted the statistical analysis and drafted the manuscript. CM, SS, DP, JP, DD, HK, FK, and PC participated in manuscript revisions. All authors read and approved the final manuscript.

Open Access This article is distributed under the terms of the Creative Commons Attribution License which permits any use, distribution, and reproduction in any medium, provided the original author(s) and the source are credited.

\section{References}

1. Smythe WR (2003) Treatment of stage I non-small cell lung carcinoma. Chest 123(1 Suppl):181S-187S

2. Armstrong JG, Minsky BD (1989) Radiation therapy for medically inoperable stage I and II non-small cell lung cancer. Cancer Treat Rev 16(4):247-255

3. Qiao X, Tullgren O, Lax I, Sirzen F, Lewensohn R (2003) The role of radiotherapy in treatment of stage I non-small cell lung cancer. Lung Cancer 41(1): 1-11

4. Baumann P, Nyman J, Hoyer M, Wennberg B, Gagliardi G, Lax I, Drugge N, Ekberg L, Friesland S, Johansson KA, Lund JA, Morhed E, Nilsson K, Levin N, Paludan M, Sederholm C, Traberg A, Wittgren L, Lewensohn R (2009) Outcome in a prospective phase II trial of medically inoperable stage I non-small-cell lung cancer patients treated with stereotactic body radiotherapy. J Clin Oncol Off J Am Soc Clin Oncol 27(20):3290-3296. doi:10.1200/JCO. 2008.21.5681

5. Grills IS, Hope AJ, Guckenberger M, Kestin LL, Werner-Wasik M, Yan D, Sonke JJ, Bissonnette JP, Wilbert J, Xiao Y, Belderbos J (2012) A collaborative analysis of stereotactic lung radiotherapy outcomes for early-stage non-small-cell lung cancer using daily online cone-beam computed tomography image-guided radiotherapy. J Thorac Oncol Off Publ Int Assoc Stud Lung Cancer 7(9):13821393. doi:10.1097/JTO.0b013e318260e00d

6. Onishi H, Shirato H, Nagata Y, Hiraoka M, Fujino M, Gomi K, Niibe Y, Karasawa K, Hayakawa K, Takai Y, Kimura T, Takeda A, Ouchi A, Hareyama M, Kokubo M, Hara R, Itami J, Yamada K, Araki T (2007) Hypofractionated stereotactic radiotherapy (HypoFXSRT) for stage I non-small cell lung cancer: updated results of 257 patients in a Japanese multi-institutional study. J Thorac Oncol Off Publ Int Assoc Stud Lung Cancer 2(7 Suppl 3):S94-S100. doi:10.1097/JTO. 0b013e318074de34

7. Timmerman R, Paulus R, Galvin J, Michalski J, Straube W, Bradley J, Fakiris A, Bezjak A, Videtic G, Johnstone D, Fowler J, Gore E, Choy H (2010) Stereotactic body radiation therapy for inoperable early stage lung cancer. JAMA J Am Med Assoc 303(11):10701076. doi:10.1001/jama.2010.261

8. Haasbeek CJ, Lagerwaard FJ, Antonisse ME, Slotman BJ, Senan S (2010) Stage I nonsmall cell lung cancer in patients aged $>$ or $=75$ years: outcomes after stereotactic radiotherapy. Cancer 116(2): 406-414. doi:10.1002/cncr.24759

9. Chang JY, Liu H, Balter P, Komaki R, Liao Z, Welsh J, Mehran RJ, Roth JA, Swisher SG (2012) Clinical outcome and predictors of survival and pneumonitis after stereotactic ablative radiotherapy for stage I non-small cell lung cancer. Radiat Oncol 7:152. doi:10.1186/ 1748-717x-7-152

10. Fakiris AJ, McGarry RC, Yiannoutsos CT, Papiez L, Williams M, Henderson MA, Timmerman R (2009) Stereotactic body radiation therapy for early-stage non-small-cell lung carcinoma: four-year results of a prospective phase II study. Int J Radiat Oncol Biol Phys 75(3):677-682. doi:10.1016/j.ijrobp.2008.11.042

11. Lagerwaard FJ, Haasbeek CJ, Smit EF, Slotman BJ, Senan S (2008) Outcomes of risk-adapted fractionated stereotactic radiotherapy for stage I non-small-cell lung cancer. Int J Radiat Oncol Biol Phys 70(3):685-692. doi:10.1016/j.ijrobp.2007.10.053

12. Nagata Y, Takayama K, Matsuo Y, Norihisa Y, Mizowaki T, Sakamoto T, Sakamoto M, Mitsumori M, Shibuya K, Araki N, Yano S, Hiraoka M (2005) Clinical outcomes of a phase I/II study of 48 Gy of stereotactic body radiotherapy in 4 fractions for primary lung cancer using a stereotactic body frame. Int J Radiat Oncol Biol Phys 63(5):1427-1431. doi:10.1016/j.ijrobp.2005.05.034

13. Senthi S, Lagerwaard FJ, Haasbeek CJ, Slotman BJ, Senan S (2012) Patterns of disease recurrence after stereotactic ablative radiotherapy for early stage non-small-cell lung cancer: a retrospective analysis. Lancet Oncol 13(8):802-809. doi:10.1016/S1470-2045(12)70242-5

14. Crabtree TD, Denlinger CE, Meyers BF, El Naqa I, Zoole J, Krupnick AS, Kreisel D, Patterson GA, Bradley JD (2010) Stereotactic body radiation therapy versus surgical resection for stage I non-small cell lung cancer. J Thorac Cardiovasc Surg 140(2):377386. doi:10.1016/j.jtcvs.2009.12.054

15. Grills IS, Mangona VS, Welsh R, Chmielewski G, McInerney E, Martin S, Wloch J, Ye H, Kestin LL (2010) Outcomes after stereotactic lung radiotherapy or wedge resection for stage I non-small-cell lung cancer. J Clin Oncol Off J Am Soc Clin Oncol 28(6):928-935. doi:10.1200/JCO.2009.25.0928

16. Verstegen NE, Oosterhuis JW, Palma DA, Rodrigues G, Lagerwaard FJ, van der Elst A, Mollema R, van Tets WF, Warner A, Joosten JJ, Amir MI, Haasbeek CJ, Smit EF, Slotman BJ, Senan S (2013) Stage I-II non-small-cell lung cancer treated using either stereotactic ablative radiotherapy (SABR) or lobectomy by video-assisted thoracoscopic surgery (VATS): outcomes of a propensity scorematched analysis. Ann Oncol Off J Eur Soc Med Oncol ESMO 24(6):1543-1548. doi:10.1093/annonc/mdt026

17. (NCCN) NCCN (2013) National comprehensive practice guidelines in oncology: non-small cell lung cancer. Natl Compr Netw 2:2014

18. Davis JN, Medbery Iii C, Sharma S, Danish A, Mahadevan A (2013) The RSSearch ${ }^{\mathrm{TM}}$ Registry: patterns of care and outcomes research on patients treated with stereotactic radiosurgery and stereotactic body radiotherapy. Radiat Oncol 8(1):275. doi:10.1186/1748-717X-8-275

19. Lagerwaard FJ, Verstegen NE, Haasbeek CJ, Slotman BJ, Paul MA, Smit EF, Senan S (2012) Outcomes of stereotactic ablative radiotherapy in patients with potentially operable stage I non-small cell lung cancer. Int J Radiat Oncol Biol Phys 83(1):348-353. doi:10.1016/j. ijrobp.2011.06.2003

20. Salazar OM, Sandhu TS, Lattin PB, Chang JH, Lee CK, Groshko GA, Lattin CJ (2008) Once-weekly, high-dose stereotactic body radiotherapy for lung cancer: 6-year analysis of 60 early-stage, 42 locally advanced, and 7 metastatic lung cancers. Int J Radiat Oncol Biol Phys 72(3):707-715. doi:10.1016/j.ijrobp.2008.01.054

21. van der Voort van Zyp NC, Prevost JB, Hoogeman MS, Praag J, van der Holt B, Levendag PC, van Klaveren RJ, Pattynama P, Nuyttens JJ (2009) Stereotactic radiotherapy with real-time tumor tracking for non-small cell lung cancer: clinical outcome. Radiother Oncol J Eur Soc Ther Radiol Oncol 91(3):296-300. doi:10.1016/j.radonc.2009. 02.011

22. Rosenzweig KE, Fox JL, Yorke E, Amols H, Jackson A, Rusch V, Kris MG, Ling CC, Leibel SA (2005) Results of a phase I doseescalation study using three-dimensional conformal radiotherapy in the treatment of inoperable nonsmall cell lung carcinoma. Cancer 103(10):2118-2127. doi:10.1002/cncr.21007 
23. Sibley GS (1998) Radiotherapy for patients with medically inoperable Stage I nonsmall cell lung carcinoma: smaller volumes and higher doses - a review. Cancer 82(3):433-438

24. Stephans KL, Djemil T, Reddy CA, Gajdos SM, Kolar M, Mason D, Murthy S, Rice TW, Mazzone P, Machuzak M, Mekhail T, Videtic GM (2009) A comparison of two stereotactic body radiation fractionation schedules for medically inoperable stage I non-small cell lung cancer: the Cleveland Clinic experience. J Thorac Oncol Off Publ Int Assoc Stud Lung Cancer 4(8):976-982. doi:10.1097/JTO. 0b013e3181adf509

25. Le QT, Loo BW, Ho A, Cotrutz C, Koong AC, Wakelee H, Kee ST, Constantinescu D, Whyte RI, Donington J (2006) Results of a phase I dose-escalation study using single-fraction stereotactic radiotherapy for lung tumors. J Thorac Oncol Off Publ Int Assoc Stud Lung Cancer 1(8):802-809

26. Nuyttens JJ, van der Voort van Zyp NC, Praag J, Aluwini S, van Klaveren RJ, Verhoef C, Pattynama PM, Hoogeman MS (2012)
Outcome of four-dimensional stereotactic radiotherapy for centrally located lung tumors. Radiother Oncol J Eur Soc Ther Radiol Oncol 102(3):383-387. doi:10.1016/j.radonc.2011.12. 023

27. Onimaru R, Fujino M, Yamazaki K, Onodera Y, Taguchi H, Katoh N, Hommura F, Oizumi S, Nishimura M, Shirato H (2008) Steep dose-response relationship for stage I nonsmall-cell lung cancer using hypofractionated high-dose irradiation by real-time tumor-tracking radiotherapy. Int J Radiat Oncol Biol Phys 70(2):374-381. doi:10.1016/j.ijrobp.2007. 06.043

28. Jeppesen SS, Schytte T, Jensen HR, Brink C, Hansen O (2013) Stereotactic body radiation therapy versus conventional radiation therapy in patients with early stage non-small cell lung cancer: an updated retrospective study on local failure and survival rates. Acta Oncol 52(7):1552-1558. doi:10. 3109/0284186X.2013.813635 